\title{
Fixed points of Bianchini mappings in metric spaces endowed with a graph
}

FLORIN BOJOR

\section{ABSTRACT.}

Let $(X, d)$ be a metric space endowed with a graph $G$ such that the set $V(G)$ of vertices of $G$ coincides with $X$. We define the notion of G-Bianchini maps and obtain a fixed point theorem for such mappings. This extends some results of other authors which involve Bianchini mappings.

DePARTMENT OF MATHEMATICS AND COMPUTER SCIENCE

NORTH UNIVERSITY OF BAIA MARE

VictORIEI 76, 430122 BAIA MARE, ROMANIA

E-mail address: f_bojor@yahoo.com

Received: 09.11.2011; In revised form: 11.12.2011; Accepted: 23.04.2012

2010 Mathematics Subject Classification. Primary 05C38, 15A15; Secondary 05A15, 15A18.

Key words and phrases. Fixed point, Picard operator, connected graph, Bianchini mapping. 